\title{
Cyclophosphamide treatment causes impairment of sperm and its fertilizing ability in mice
}

\author{
Namasivayam Elangovan ${ }^{\text {a }}$, Tzeon-Jye Chiou ${ }^{\mathrm{c}, \mathrm{d}}$, \\ Woan-Fang Tzeng ${ }^{\mathrm{e}}$, Sin-Tak Chu ${ }^{\mathrm{a}, \mathrm{b}, *}$ \\ ${ }^{a}$ Institute of Biochemical Science, College of Life Science, National Taiwan University, Taipei, Taiwan, ROC \\ ${ }^{\mathrm{b}}$ Institute of Biological Chemistry, Academia Sinica, Taipei, Taiwan, ROC \\ ${ }^{\mathrm{c}}$ Section of Medical Oncology, Department of Medicine, Veterans General Hospital, Taipei, Taiwan, ROC \\ ${ }^{\mathrm{d}}$ School of Medicine, National Yang-Ming University, Taipei, Taiwan, ROC \\ e Department of Life Science, Fu Jen University, Taipei, Taiwan, ROC
}

Received 9 September 2005; received in revised form 23 January 2006; accepted 23 January 2006

Available online 6 March 2006

\begin{abstract}
This study is focused on the toxicological effect of cyclophosphamide on male mice reproductive system. In the present study, cyclophosphamide was injected intraperitoneally (ip) at the level of $50-200 \mathrm{mg} / \mathrm{kg}$ body weight into 6-weeks old ICR male mice once in a week for a period of 5 weeks. The animals were sacrificed after 1st and 5th week of last injection. Reduction in weight of testis and epididymis were observed both in 1st and 5th week group mice after administration with increasing concentration of cyclophosphamide. The weight of the body significantly decreased in both $1 \mathrm{st}$ and 5 th week group in mice treated with $200 \mathrm{mg} / \mathrm{kg}$ cyclophosphamide. The weight of the testis significantly decreased with all doses of cyclophosphamide in 1st week group, whereas, in 5th week group significant reduction was observed only in $200 \mathrm{mg} / \mathrm{kg}$ dose of cyclophosphamide. The sperm motility was analyzed with Computer-Assisted Sperm Analysis (CASA). The motility of caudal sperm decreased with increasing concentration of cyclophosphamide in the 1st week group, whereas, it revived after 5th week. The total sperm counts in the epididymis of 1 st week group mice declined significantly while significant restoration of the same was observed with mice treated with 50,100 and $150 \mathrm{mg} / \mathrm{kg}$ doses in the 5th week group. The intact acrosome was lower with 150 and $200 \mathrm{mg} / \mathrm{kg}$ doses in both $1 \mathrm{st}$ and 5 th week group. The live sperm was reduced to $29 \%$ in mice treated with $200 \mathrm{mg} / \mathrm{kg}$ in the 5 th week group. The decrease in the pregnancy rate of female mice was 17, 50, 58 and $100 \%$ when mated with male mice injected with 50,100,150 and $200 \mathrm{mg} / \mathrm{kg}$ dose, respectively. Seminiferous tubules of mouse testis were severely damaged in the 1st week group. However, reinstate of sperm within the seminiferous tubules was observed in the 5th week group mice. Significant decrease in serum luteinizing hormone (LH) was observed in the 1 st week group treated with $50,100,150$ and $200 \mathrm{mg} / \mathrm{kg}$ dose of cyclophosphamide. However, no significant difference was observed in the serum follicle-stimulating hormone (FSH), whereas, a decrease of about $98 \%$ in serum testosterone level was observed in cyclophosphamide treated mice. The decrease in the mean testosterone levels of cyclophosphamide treated mice served as proof for the damage of testis. These results demonstrate that cyclophosphamide caused temporary interference of normal male reproductive system with low dose treatment, but might be permanent dysfunction in high dose treatment.
\end{abstract}

(C) 2006 Elsevier Ireland Ltd. All rights reserved.

Keywords: Cyclophosphamide; Epididymis; Follicle-stimulating hormone; Luteinizing hormone; Sperm motility; Testis; Testosterone

\footnotetext{
* Corresponding author. Tel.: +8862 23620261; fax: +886223635038.

E-mail address: stc316@gate.sinica.edu.tw (S.-T. Chu).
} 


\section{Introduction}

Cyclophosphamide belonging to the class of oxazaphosphorines, is a bioactivated metabolite and alkylating agent that show cytostatic effects by forming covalent DNA adducts. The cytotoxicity of cyclophosphamide is mediated by alkylation of DNA at the N7 position of guanine and the formation of DNA-DNA cross-links, DNA-protein cross-links, and single-strand breaks (Hemminki and Kallama, 1986; Crook et al., 1986). Cyclophosphamide therapy is a common continuing problem in the treatment of a variety of glomerular diseases and leads to gonadal toxicity as a side effect of the drug. The consequences of infertility can have great physical and emotional impact on both men and women. Hence, this issue often has a critical role in deciding whether or not to undergo treatment with cyclophosphamide. Cyclophosphamide is extensively used as anticancer malignancies, as well as an immunosuppressive agent for organ transplantation (Dollery, 1999), leukemia, Hodgkin's disease, etc. The cytotoxic effect of cyclophosphamide targets rapidly dividing cells and testis is especially a good target for damaging effects. In spite of its therapeutic importance, a wide range of adverse effects including reproductive toxicity has been demonstrated following cyclophosphamide treatment in patients and in experimental animals. Decrease in weight of reproductive organ, impaired fertility, growth and development of next generation was also observed in low dose cylophosphamide treated male rats (Trasler et al., 1986). The cancer male patients treated with cyclophosphamide exhibited an increased incidence of oligospermia and azoospermia (Charak et al., 1990; Kenney et al., 2001). A single injection of high-dose cyclophosphamide during the development of mouse spermatocytes resulted in heritable translocations (Sotomayor and Cumming, 1975) and increased the incidence of micronuclei (Tates, 1992; Lahdetie, 1983, 1988). The reversal of fertility was unpredictable in drug treated patients but in some cases, it took more number of years (Buchanan et al., 1975). The male patients treated with cyclophosphamide have demonstrated disturbed gonadotrophin secretion associated with testicular damage along with low blood level of testosterone (HoorwegNijman et al., 1992). Cyclophosphamide treatment at its therapeutic dose in rat resulted in inhibition of gonadal steroidogenesis (Ghosh et al., 2002). In the testis, cyclophosphamide disrupts meiotic events during spermatogenesis before pachytene stage thus emphasizing the potential for adverse progeny outcomes due to genotoxic damage. To maintain genomic stability, eukaryotic cells respond to genetic damage by arresting or delaying cell cycle progression. Such delay, allows for the activation of DNA repair mechanisms, or when the damage is too overwhelming, of cell death pathways (Sancar et al., 2004). The morphometric study of different stages in spermatogenic cycle indicates that testicular toxicity can be detected from day 7 even after a single oral administration of cyclophosphamide $(100 \mathrm{mg} / \mathrm{kg})$ in rat (Matsui et al., 1995).

Cell cycle impairment induced after acute cyclophosphamide treatment could be mediated by G2/M activated in response to DNA damage (Aguilar-Mahecha et al., 2005). The literature survey revealed that the correlation between permanent and temporary loss of fertility is not well established. The first objective of this study was to elucidate the impact of acute or chronic cyclophosphamide exposure on spermatogenesis, fertility and to determine how the levels of sperm viability induced by cyclophosphamide exposure affect progression in spermatogenesis. The second objective of this study was to determine the toxicological effect of cyclophosphamide on sperm activity, fertile capacity and sexual hormone levels in mice treated with anticancer drug cyclophosphamide. Based on the above two objectives, this work was designed to assess the effect of cyclophosphamide treatment for five continuous week (once a day in a week) on male reproductive system which included the fertility outcome with respect to spermatogenesis.

\section{Materials and methods}

\subsection{Experimental animals}

Outbred ICR mice were purchased from Charles River Laboratories (Wilmington, MA, USA). They were bred in the animal center at the College of Medicine (National Taiwan University, Taipei, Taiwan). Animals were treated in accordance with the institutional guidelines for care and use of experimental animals. The test animals were kept under controlled lighting ( $14 \mathrm{~h}$ light $/ 10 \mathrm{~h}$ dark) at a constant temperature $\left(23 \pm 2{ }^{\circ} \mathrm{C}\right)$ with water and $\mathrm{NIH} 31$ laboratory mouse chow supplied ad libitum. The male mice (6 weeks old) were grouped $n \leq 3$ throughout the experiment.

\subsection{Experimental design}

Cyclophosphamide (CAS no. 6055-19-2; Sigma, St. Louis, MO, USA) was dissolved in PBS and injected intraperitoneally (ip) to the mice, once in a week for a period of 5 weeks. The $\mathrm{LD}_{50}$ value of cyclophosphamide in mouse was $250 \mathrm{mg} / \mathrm{kg}$ of body weight. The cyclophosphamide was administered at a level of 50,100, 150 and $200 \mathrm{mg} / \mathrm{kg}$ body weight $(2,4,6$ and $8 / 10$ th of $\mathrm{LD}_{50}$, respectively). The highest dose corresponded to the therapeutic dose of humans. The recommended dose 
of cyclophosphamide in humans in the management of lymphoma and BMT are $750 \mathrm{mg} / \mathrm{m}^{2}$ once in a month for a period of 4-6 months. The conversion factor for the animal (mouse $=3$ ) dose in $\mathrm{mg} / \mathrm{kg}$ to obtain the equivalent dose in $\mathrm{mg} / \mathrm{m}^{2}$ for the human was $210-220 \mathrm{mg} / \mathrm{kg}$ mouse body weight (Freireich et al., 1966). The control mice received PBS vehicle throughout the experiment. After 1st and 5th week of last injection, the animals were sacrificed by cervical dislocation and the body weight was determined. From here on the animals sacrificed after 1st week and 5th week of last injection shall be referred to as 1 st week and 5th week group, respectively.

Blood was collected by cardiac puncture without anticoagulant. Serum was separated and stored at $-70{ }^{\circ} \mathrm{C}$ for enzyme immunoassays of LH, FSH and testosterone. Epididymis and testes were quickly dissected out and weighed. Testes were fixed in Bouin's fixative ( $0.2 \%$ picric acid/2\% (v/v) formaldehyde in PBS) for histological evaluation.

\subsection{Sperm motility and count}

In order to assess the sperm motility, one caudal epididymis was placed in Modified HEPES Medium (HM) (Lee and Storey, 1986) without $\mathrm{CaCl}_{2}$ or BSA. The $\mathrm{HM}$ medium contained $\mathrm{NaCl}$ (120 mM), $\mathrm{KCl}(2 \mathrm{mM}), \mathrm{MgSO}_{4} \cdot 7 \mathrm{H}_{2} \mathrm{O}$ (1.2 mM), $\mathrm{NaH}_{2} \mathrm{PO}_{4}$ $(0.36 \mathrm{mM}), \mathrm{NaHCO}_{3}(25 \mathrm{mM})$, HEPES (10 mM), glucose $(5.6 \mathrm{mM})$, sodium pyruvate $(1.1 \mathrm{mM})$, penicillin $(100 \mathrm{IU} / \mathrm{ml})$, and streptomycin $(100 \mu \mathrm{g} / \mathrm{ml})$. The $\mathrm{pH}$ of the medium was adjusted to 7.1 to 7.3 by aeration with humidified air/ $\mathrm{CO}_{2}$ $(19: 1 \mathrm{v} / \mathrm{v})$. Cauda was cut into $2-3$ pieces and incubated at $37^{\circ} \mathrm{C}$ for $10 \mathrm{~min}$ in $\mathrm{CO}_{2}$ incubator. The sperm was gently filtered through nylon gauze and the filtrates (spermatozoa) were used to analyze sperm motility by computer-assisted sperm assay (CASA) with a sperm motility analyzer (IVOS version 10; Hamilton-Thorne Research, Beverly, MA, USA).

The epididymal sperm count was determined by hemocytometer. Briefly, epididymis was placed in the HM medium, macerated and incubated in $\mathrm{CO}_{2}$ incubator at $37^{\circ} \mathrm{C}$ for $10 \mathrm{~min}$. The cells were filtered through a double gauze layer and an aliquot of the sample was used for sperm count in hemocytometer. The sperm count was expressed as number of sperm per milliliter.

\subsection{Assessment of acrosome integrity}

The sperm suspension was incubated in $\mathrm{CO}_{2}$ incubator for $30 \mathrm{~min}$ and a drop of sperm suspension was uniformly smeared on clean glass slide. Smeared slides were air dried and incubated in methanol for $2 \mathrm{~min}$ for fixation. After fixation, the slides were washed with PBS for three times. Assessment of intact acrosome status was accomplished by staining the sperm with $0.025 \%$ Coomassie brilliant blue G-250 in $40 \%$ methanol for $20 \mathrm{~min}$ at room temperature. The slides were then washed three times with PBS and mounted with $50 \%$ glycerol in PBS. The acrosome integrity was assayed by an intense staining on the anterior region of sperm head under bright-field microscopy (AH3-RFCA, Olympus, Tokyo, Japan) and scored for acrosomal staining.

\subsection{Viability of spermatozoa}

Sperm viability was evaluated by acridine orange fluorescence of sperm nuclei (Hoshi et al., 1996). Caudal spermatozoa were smeared on clean glass side. The smear was stained with $4 \mathrm{ng} / \mathrm{ml}$ acridine orange (Sigma, St. Louis, MO, USA) for $2 \mathrm{~min}$ followed by counterstaining with $0.5 \mathrm{ng} / \mathrm{ml}$ propidium iodide (Sigma, St. Louis, MO, USA) for $1 \mathrm{~min}$. The stained slides were examined in dark room using an Olympus epifluorescence microscope. Live spermatozoa fluoresced to green in the midpiece region, while damaged spermatozoa fluoresced to red in the head region.

\subsection{Study of male fertility}

Cyclophosphamide administered male mice (one number, 11 weeks old) was grouped with three untreated healthy female mice (6 weeks old), and provided with standard pelleted chow. The reproductive toxicity of cyclophosphamide treated mice was tested with the number of offspring born in the 1st week group. For each dose, one male was grouped with three female mice and a total of four cages (i.e. 12 females) were used for a single dose. The females were examined every day. The presence of vaginal mucous plug was taken as day 0 of gestation for the mated females and considered as impregnated female mice. The mating trials were continued until 20 weeks when each male had impregnated the untreated female mice. The number of pregnant females and litter size was noted in the control and cyclophosphamide-treated groups.

\subsection{Histology}

For histological studies, the testis was fixed overnight in Bouin's fluid, dehydrated in ethanol, and embedded in paraffin. Tissue sections $(6 \mu \mathrm{m})$ were mounted on glass slide coated with aminoalkylsilane (St. Louis, MO, USA) and dried at $42{ }^{\circ} \mathrm{C}$ for $24 \mathrm{~h}$. The sections were then deparafinized with xylene, rehydrated with alcohol and water. The rehydrated sections were stained with haematoxylin and eosin, mounted with $50 \%$ glycerol in PBS and examined under a light microscope (AH3RFCA, Olympus, Tokyo, Japan).

\subsection{Hormone assays}

Serum concentrations of follicle-stimulating hormone (FSH), luteinizing hormone ( $\mathrm{LH})$ and testosterone were measured by enzyme-linked immunosorbent assay (ELISA) as described in the instructions provided by manufacturer's kits (Immuno-Biological Laboratories, Hamburg, Germany).

\subsection{RT-PCR for the expression of steroidogenic enzymes}

Enzymes involved in the testicular biosynthetic pathway of testosterone were screened by expression of P450scc and $3 \beta$ HSD in mouse testis. Total RNA was extracted from testes of cyclophosphamide treated and untreated animals $(n=4)$ 
Table 1

Primers used for semiquantitative RT-PCR analyses

\begin{tabular}{lllllll}
\hline Genes & Forward primer & Reverse primer & $\begin{array}{l}\text { Product } \\
\text { size (bp) }\end{array}$ & $\begin{array}{l}\text { PCR } \\
\text { cycle }\end{array}$ & $\begin{array}{l}\text { Annealing } \\
\text { temperature } \\
\left({ }^{\circ} \mathrm{C}\right)\end{array}$ & $\begin{array}{l}\text { GenBank } \\
\text { accession no. }\end{array}$ \\
\hline$\beta$-Actin & ATGGATGACGATATCGCTGCGCTG & ATGAGGTAGTCTGTCAGGT & 481 & 25 & 58 & X03672 \\
$P 450 s c c$ & CGCTCAGTGCTGGTCAAAG & GGTTGAGCATGG GGACACT & 714 & 30 & 55 & AF195119 \\
$3 \beta-H S D$ & GCAGACCATCCTAGATGTCAATCTG & CAAGTGGCTCATAGCCCAGATCTC & 749 & 25 & 55 & M58567 \\
\hline
\end{tabular}

using RNeasy Mini kit (Qiagen, Germany). The expression of mRNA was analyzed with RT-PCR. The nucleotide sequences of primer pairs used for PCR are shown in Table 1 . The cDNA was synthesized from total RNA with oligo dT primer, reverse transcribed and amplified by PCR using one-step RTPCR kit according to the manufacturer's instructions (Qiagen, Germany). The reaction products were fractionated on $1.2 \%$ agarose gels and visualized with ethidium bromide. Product yield was determined using TotalLab Software, Version 2.01, ImageMaster, Amersham Pharmacia Biotech, USA. Data were quantified by normalizing with the PCR product of $\beta$-actin.

\subsubsection{Statistical analysis}

All statistical analysis were conducted using One-way ANOVA with Dunnett's post test using GraphPad InStat version 3.00 for Windows, GraphPad Software, San Diego, CA, USA.

\section{Results}

\subsection{Body and organ weights}

The body weight of experimental animals treated with cyclophosphamide differed from the control ani- mals in 1 st and 5 th week group $(P<0.05$ in higher dose) (Table 2). The relative weights of testis and epididymis are shown in Table 2 . The relative weight of the testis significantly decreased in dose-dependent cyclophosphamide treated animals of 1st week group $(P<0.001)$, whereas, significant difference was found only in $200 \mathrm{mg} / \mathrm{kg}$ in the 5 th week group $(P<0.001)$. No changes were found in the relative epididymal weight in 1st week group, whereas, significant weight loss was found with higher dose $(200 \mathrm{mg} / \mathrm{kg})$ in 5 th week group mice.

\subsection{Sperm motility and counts}

The motility of cauda epididymal sperm decreased with increasing concentrations of cyclophosphamide in 1st week group. There was significant decrease in motility $(P<0.01$ and $P<0.001)$ in 150 and $200 \mathrm{mg} / \mathrm{kg}$ dose of 1 st week group when compared to the control (Fig. 1A). In the 5th week group, motility recovered in all doses except in $200 \mathrm{mg} / \mathrm{kg}$ dose (Fig. 1B). These results indicate that sperm motility is revived after 5 th week of last cyclophosphamide treatment.

Table 2

Effect of cyclophosphamide on the body weight, weights of testis and epididymis after 1st and 5th weeks of last injection

\begin{tabular}{lccccc}
\hline & \multicolumn{2}{l}{ Cyclophosphamide (mg/kg of body weight) } & & \\
\cline { 2 - 6 } & Control & 50 & 100 & 150 & 200 \\
\hline No. of mice examined after 1st week & 5 & 5 & 5 & 5 & 5 \\
Body weight (g) & $40.40 \pm 3.64$ & $39.40 \pm 2.60$ & $35.0 \pm 3.53$ & $36.20 \pm 4.14$ & $30.0 \pm 7.07^{*}$ \\
Testis (mg) & $114.96 \pm 16.25$ & $84.26 \pm 22.24^{* * * *}$ & $64.58 \pm 15.01^{* * *}$ & $50.34 \pm 11.14^{* * *}$ & $39.35 \pm 4.81^{* * * *}$ \\
Testis (mg/g b.wt.) & $2.74 \pm 0.42$ & $2.16 \pm 0.68^{* *}$ & $1.85 \pm 0.45^{* * *}$ & $1.48 \pm 0.39^{* * *}$ & $1.17 \pm 0.11^{* * * *}$ \\
Epididymis (mg) & $44.19 \pm 4.78$ & $42.43 \pm 2.56$ & $35.22 \pm 3.71^{* * *}$ & $34.55 \pm 2.24^{* * *}$ & $29.77 \pm 5.18^{* * * *}$ \\
Epididymis (mg/g b.wt) & $1.10 \pm 0.20$ & $1.08 \pm 0.10$ & $1.00 \pm 0.09$ & $0.96 \pm 0.09$ & $1.00 \pm 0.13$ \\
No. of mice examined after 5th weeks & 4 & 4 & 4 & 4 & 3 \\
Body weight (g) & $37.42 \pm 2.80$ & $39.52 \pm 3.32$ & $37.55 \pm 2.94$ & $33.15 \pm 1.62$ & $28.33 \pm 5.77^{*}$ \\
Testis (mg) & $127.48 \pm 23.36$ & $122.2 \pm 16.35$ & $103.55 \pm 8.89$ & $103.91 \pm 23.76$ & $71.28 \pm 13.92^{* * *}$ \\
Testis (mg/g b.wt.) & $3.41 \pm 0.65$ & $3.09 \pm 0.39$ & $2.76 \pm 0.22$ & $3.14 \pm 0.74$ & $2.53 \pm 0.47^{*}$ \\
Epididymis (mg) & $49.92 \pm 4.15$ & $48.62 \pm 8.07$ & $45.32 \pm 1.2$ & $45.61 \pm 4.20$ & $31.13 \pm 624^{* * *}$ \\
Epididymis (mg/g b.wt) & $1.33 \pm 0.13$ & $1.23 \pm 0.19$ & $1.21 \pm 0.09$ & $1.37 \pm 0.14$ & $1.09 \pm 0.05^{*}$ \\
\hline
\end{tabular}

The values are expressed as mean \pm S.D.

* Significantly different from control groups, $P<0.05$.

*** Significantly different from control groups, $P<0.001$. 

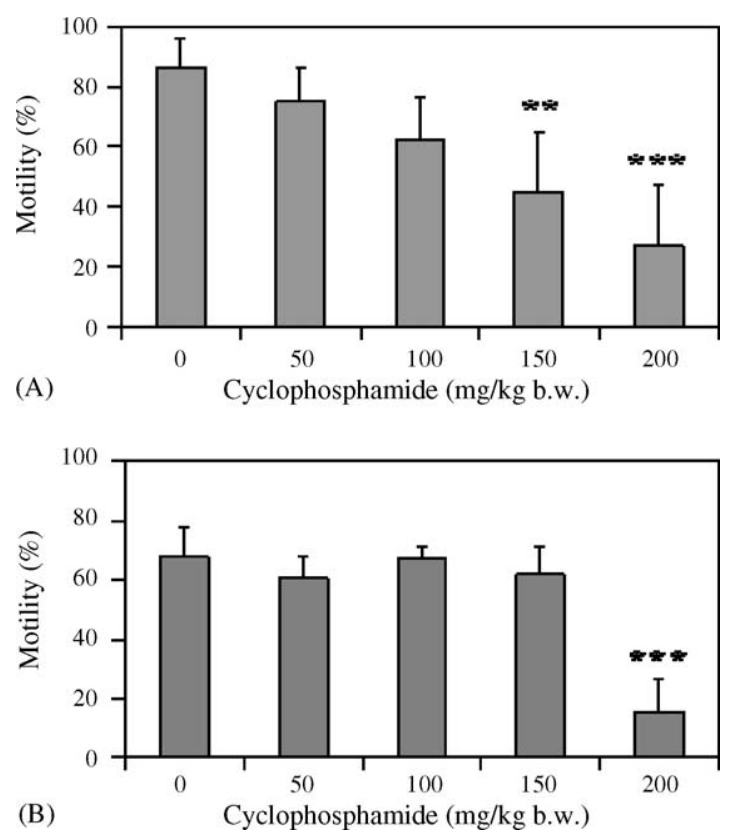

Fig. 1. Effect of cyclophosphamide treatment on the sperm motility (A) after 1st week and (B) after 5th week of last injection. Values are expressed as mean \pm S.D., $n=4$ in each group, ${ }^{* *} P<0.01$, ${ }^{* * * *} P<0.001$ compared with control groups.

The sperm count in the epididymis of 1 st week group mice declined significantly when compared to the control. Comparison of the sperm counts among 1 st week group mice treated with 100,150 and $200 \mathrm{mg} / \mathrm{kg}$ doses indicated significant reduction when compared to the control $(65,91$ and $91 \%$, respectively) (Fig. 2A). The effect observed in 150 and $200 \mathrm{mg} / \mathrm{kg}$ cyclophosphamide group of the 5th week was that a decrease in sperm count up to 31 and $84 \%(P<0.001)$, whereas, there was no change in sperm count in 50 and $100 \mathrm{mg} / \mathrm{kg}$ doses treated mice (Fig. 2B). Compared to 1 st week group, there was significant restoration of sperm count in 50,100 and $150 \mathrm{mg} / \mathrm{kg}$ doses in the 5th week group, whereas, no changes were observed in $200 \mathrm{mg} / \mathrm{kg}$ dose animals. All of these data does coincide with the data of organ weights suggesting restoration of organ weights with restoration of cell number.

\subsection{Integrity of acrosome and sperm viability}

The percentage of sperm with intact acrosome was significantly lower in 50,150 and $200 \mathrm{mg} / \mathrm{kg}$ dose treated 1 st week group mice when compared to the control animals. In the 5th week group, mice treated with 50, 100, 150 and $200 \mathrm{mg} / \mathrm{kg}$ dose there was $9,16,33$ and $59 \%$
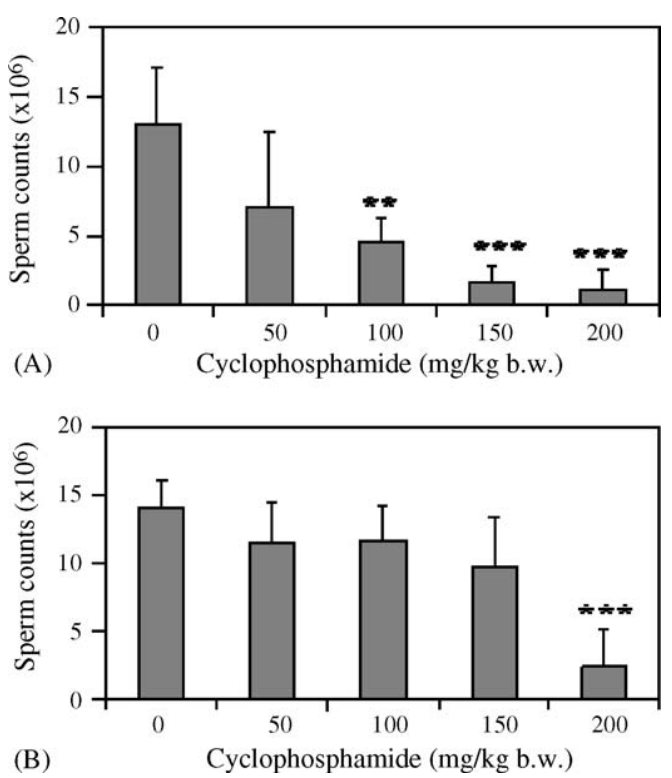

Fig. 2. Effect of cyclophosphamide treatment on the sperm count (A) after 1 week and (B) after 5 weeks of last injection. Values are expressed as mean \pm S.D., $n=4$ in each group, ${ }^{* *} P<0.01,{ }^{* * *} P<0.001$ compared with control groups.

decrease in intact acrosome, respectively, when compared to the control (Table 3). Intact acrosome of sperm may indicate the sperm with integrity, but not really with fertility.

Out of the total sperm content in cauda epididymis, sperm viability was assessed based on the sperm number. No significant difference in cauda epididymal sperm viability (live \%) was observed in 1st week group mice, whereas, the live sperm content was reduced up to $20 \%$ in 150 and $200 \mathrm{mg} / \mathrm{kg}$ groups when compared to the control. However, significant $(P<0.01)$ reduction in live sperm was found in 100,150 and $200 \mathrm{mg} / \mathrm{kg}$ dose of 5th week group compared to the control (Table 3).

\subsection{Fertility}

No significant changes were observed in the pregnancy rates of cyclophosphamide treated male-mated female mice in any of the doses in 1st week group. Interestingly, there was 17, 50, 59 and $100 \%$ decrease in the pregnancy rates of females in mice treated with 50, 100, 150 and $200 \mathrm{mg} / \mathrm{kg}$ dose, respectively, when compared to control. However, no females were impregnated in $200 \mathrm{mg} / \mathrm{kg}$ dose even after 20 weeks (Table 3). Permanent sterility was observed in male mice treated with $200 \mathrm{mg} / \mathrm{kg}$ dose. 
Table 3

Effect of cyclophosphamide on the acrosome reaction and fertility after 1 and 5 weeks of last injection

\begin{tabular}{|c|c|c|c|c|c|}
\hline & \multicolumn{5}{|c|}{ Cyclophosphamide (mg/kg of body weight) } \\
\hline & Control & 50 & 100 & 150 & 200 \\
\hline \multicolumn{6}{|l|}{ After 1 week } \\
\hline Intact acrosome $(\%)$ & $100.00 \pm 6.70$ & $64.91 \pm 24.16^{*}$ & $71.43 \pm 5.13$ & $55.38 \pm 14.46^{* *}$ & $51.38 \pm 5.00^{* * *}$ \\
\hline Live sperm $(\%)$ & $100.00 \pm 5.32$ & $90.38 \pm 15.16$ & $81.32 \pm 4.73$ & $81.76 \pm 7.93$ & $81.46 \pm 9.85$ \\
\hline Fertility no. of offspring born & $11.58 \pm 1.50$ & $9.90 \pm 4.09$ & $9.33 \pm 1.75$ & $11.20 \pm 3.11$ & $-^{\mathrm{a}}$ \\
\hline Number of female impregnated & 12 & 10 & 6 & 5 & 0 \\
\hline \multicolumn{6}{|l|}{ After 5 weeks } \\
\hline Intact acrosome $(\%)$ & $100.00 \pm 23.24$ & $90.75 \pm 5.33$ & $83.81 \pm 38.24$ & $66.83 \pm 15.66$ & $41.13 \pm 13.45^{*}$ \\
\hline Live sperm $(\%)$ & $100.00 \pm 2.53$ & $91.00 \pm 8.79$ & $77.73 \pm 12.87^{*}$ & $74.50 \pm 4.61^{*}$ & $71.36 \pm 0.78^{*}$ \\
\hline
\end{tabular}

The values are expressed as mean \pm S.D., $n=4$.

${ }^{*}$ Significantly different from control groups, $P<0.05$.

** Significantly different from control groups, $P<0.01$.

**** Significantly different from control groups, $P<0.001$.

${ }^{\text {a }}$ No females delivered offspring.

\subsection{Testicular histological observation}

Morphological alterations were produced in the seminiferous tubules in mice treated with 100 (Fig. 3C and D) and $200 \mathrm{mg} / \mathrm{kg}$ (Fig. 3E and F) dose in the $1 \mathrm{st}$ and 5 th week group. In the 1 st week group, with $100 \mathrm{mg} / \mathrm{kg}$ dose treated mice (Fig. 3C) the seminiferous tubule showed less number of sperm, whereas, in $200 \mathrm{mg} / \mathrm{kg}$ dose treated groups (Fig. 3E) it was severely damaged. In the 5th week group less damage of sperm in seminiferous tubule with $100 \mathrm{mg} / \mathrm{kg}$ dose treated mice was observed when (Fig. 3D) compared to that in the 1st week group (Fig. 3C). In contrast, histological sections of seminiferous tubules in the testis from 5th week group mice (Fig. 3D and F) showed reinstating of sperm when compared with the 1st week group mice (Fig. 3C and E). In the mice treated with $200 \mathrm{mg} / \mathrm{kg}$ dose in 1 st week the spermatogonia (sg) and spermatids (sd) in the testis were completely damaged. There was no significant difference in the spermatogonia, of 1 st and 5th week group of $100 \mathrm{mg} / \mathrm{kg}$ cyclophosphamide treated mice (Fig. 3C and D). However, mice treated with higher dose $(200 \mathrm{mg} / \mathrm{kg})$ of cyclophosphamide in both $1 \mathrm{st}$ and 5 th week showed damaged and decreased number of spermatogonial cells in the testis (Fig. 3E and F). Spermatocytes (sc) and spermatids in cyclophosphamide treated testis were markedly decreased, when compared to the control. Moreover, the size of the seminiferous tubule decreased with increasing concentration of cyclophosphamide. The results from this study show that spermatozoa in testis respond differentially to the damaging effects of acute and chronic cyclophosphamide exposure and provide further evidence in support of the existence of seminiferous tubule damage.

\subsection{Serum hormone levels}

The mean serum FSH, LH and testosterone levels in the cyclophosphamide treated and control mice are presented in Table 4. There was significant increase in mean LH levels $(\mathrm{ng} / \mathrm{ml})$ of 1 st week group irrespective of cyclophosphamide concentration when compared to the control mice. However, no significant difference was observed in $\mathrm{LH}$ of 5th week group. The mean FSH levels also remained unchanged when compared to the control in both 1st and 5th week group. On the other hand, in mice treated with $200 \mathrm{mg} / \mathrm{kg}$ dose the FSH level considerably decreased in both 1st and 5th week group. The mean testosterone level in $50,100,150$ and $200 \mathrm{mg} / \mathrm{kg}$ doses of 1 st week group showed significant differences $(P<0.01)$ when compared to that of the control. Similarly in 5th week group, there was significant differences $(P<0.001)$ in testosterone level. The testosterone level decreased to about $98 \%$ in cyclophosphamide treated mice when compared to that of the control. The difference in the mean testosterone levels between the cyclophosphamide treated and control mice served as evidence for the damage of the testis. The degeneration of spermatogonium can be related to the low level of testosterone in the serum.

\subsection{Steroidogenic gene expression of P450scc and $3 \beta-H S D$}

We examined possible effects of cyclophosphamide on the mRNA expression of two testosterone biosynthetic pathway enzymes, P450scc and $3 \beta-\mathrm{HSD}$, in the mouse testis. P450scc and $3 \beta-\mathrm{HSD}$ are reflection of 

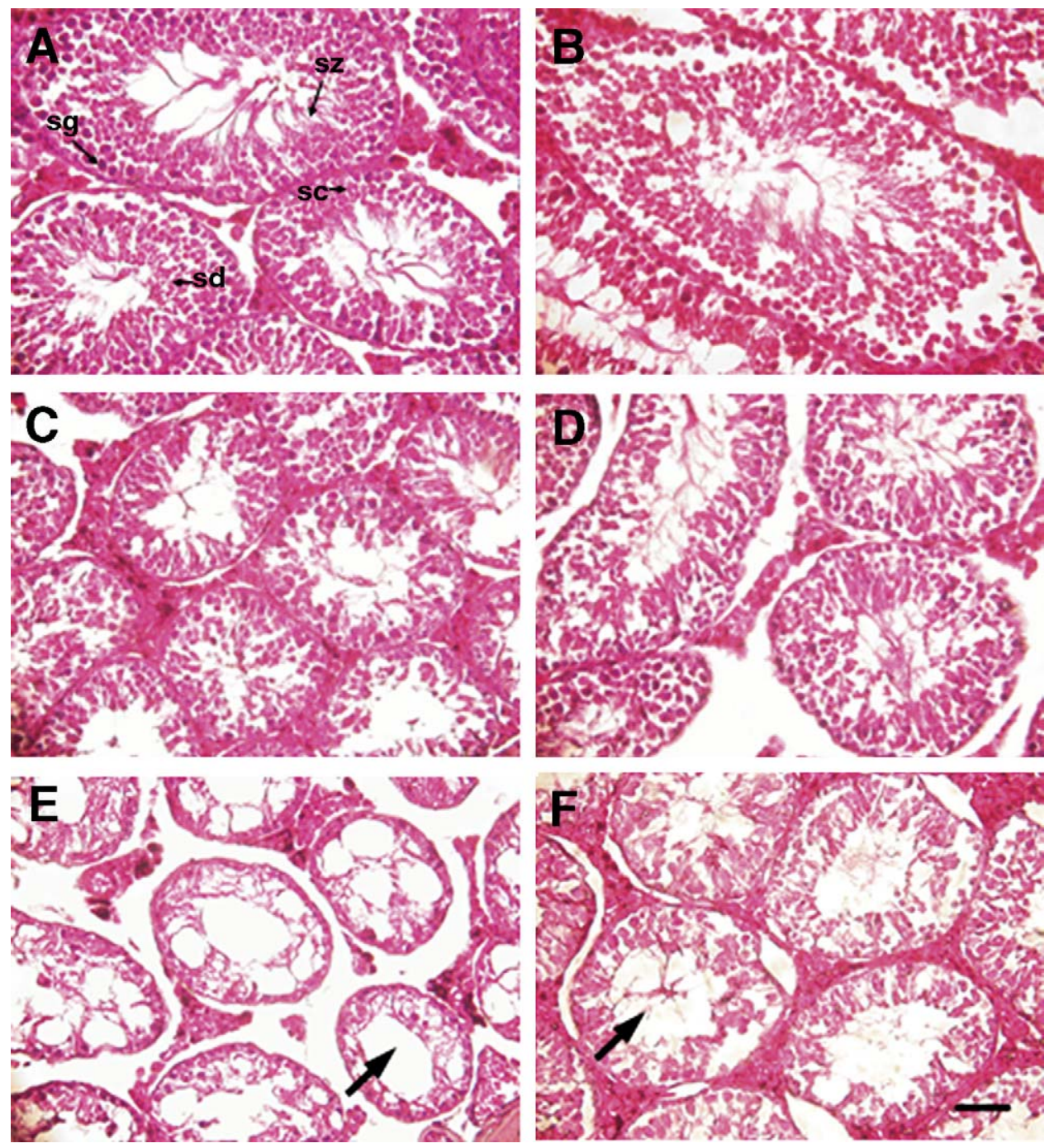

Fig. 3. Histological effects of cyclophosphamide on the mouse testis. Mice were injected with 100 and $200 \mathrm{mg} / \mathrm{kg}$ cyclophosphamide (C and E, respectively). After 5 th week of last injection group, with 100 and $200 \mathrm{mg} / \mathrm{kg}$ of cyclophosphamide, testis was collected as shown in (D) and (F), respectively. Control testis obtained after 1st (A) and 5th (B) week of last ip injection of PBS showing the normal seminiferous tubule and spermatogenesis. sg, spermatogonia; sc, spermatocytes; sd, spermatids; sz, spermatozoa. Scale bar $0.06 \mathrm{~mm}$.

intratesticular testosterone (IIT) concentration. When cyclophosphamide was administered at a dose of 0 , $50,100,150$ or $200 \mathrm{mg} / \mathrm{kg}$ dose in adult mice, the expression of $3 \beta-H S D$ was up regulated in a dosedependent manner in 1 st week. Significant increase was observed in $200 \mathrm{mg} / \mathrm{kg}$ dose $(P<0.01)$ of $3 \beta-H S D$, whereas, no significant changes were observed in expression of P450scc in 1st week (Fig. 4A). Similarly, no significant difference in the expression of P450scc and $3 \beta$-HSD was observed in the cyclophosphamide treated mice in 5th week by semiquantitative RT-PCR analysis (Fig. 4B).

\section{Discussion}

Mouse models provide an attractive alternate for humans to carry out the toxicological study of cancer drugs involved in spermatogenesis. In this study, we demonstrate the dose-response relationship for the effect of cyclophosphamide on the weight of testis, sperm motility and sperm count. The result is correlated to changes in the spermatogenesis (Fig. 3). The sperm viability, fertility and level of testosterone corresponded to the dose dependent damage in testicular cells. Effective anticancer and immunosuppressive therapy with 
Table 4

Effect of cyclophosphamide on the hormones after 1 and 5 weeks of last injection

\begin{tabular}{|c|c|c|c|c|c|}
\hline & \multicolumn{5}{|c|}{ Cyclophosphamide (mg/kg of body weight) } \\
\hline & Control & 50 & 100 & 150 & 200 \\
\hline \multicolumn{6}{|l|}{ After 1 week } \\
\hline $\mathrm{LH}(\mathrm{ng} / \mathrm{ml})$ & $0.64 \pm 0.17$ & $0.36 \pm 0.18^{*}$ & $0.23 \pm 0.08^{* *}$ & $0.11 \pm 0.09^{* * *}$ & $0.07 \pm 0.06^{* * *}$ \\
\hline FSH (ng/ml) & $3.14 \pm 2.64$ & $2.38 \pm 1.74$ & $1.03 \pm 0.97$ & $1.12 \pm 1.06$ & $1.88 \pm 0.75$ \\
\hline Testosterone (ng/ml) & $7.03 \pm 3.32$ & $0.52 \pm 0.07^{* *}$ & $0.27 \pm 0.07^{* *}$ & $0.20 \pm 0.01^{* *}$ & $0.17 \pm 0.02^{* *}$ \\
\hline \multicolumn{6}{|l|}{ After 5 weeks } \\
\hline LH (ng/ml) & $0.25 \pm 0.15$ & $0.25 \pm 0.11$ & $0.26 \pm 0.05$ & $0.19 \pm 0.06$ & $0.08 \pm 0.05$ \\
\hline FSH (ng/ml) & $4.24 \pm 2.50$ & $2.92 \pm 1.20$ & $2.26 \pm 1.44$ & $2.39 \pm 1.15$ & $1.57 \pm 2.23$ \\
\hline Testosterone (ng/ml) & $10.02 \pm 3.15$ & $0.38 \pm 0.10^{* * *}$ & $0.23 \pm 0.03^{* * *}$ & $0.21 \pm 0.04^{* * *}$ & $0.13 \pm 0.08^{* * *}$ \\
\hline
\end{tabular}

The values are expressed as mean \pm S.D., $n=4$.

${ }^{*}$ Significantly different from control groups, $P<0.05$.

** Significantly different from control groups, $P<0.01$.

*** Significantly different from control groups, $P<0.001$.

cyclophosphamide is severely limited by testicular toxicity as documented in a variety of species (Fraiser et al., 1991). Furthermore, it has been reported that chronic low dose administration of cyclophosphamide can decrease reproductive organ weights (Das et al., 2002), impair male fertility (Trasler et al., 1986), and alter growth and development of the next generation (Higuchi et al., 1995). In the present study, reduction in body weight, weight of the testis and epididymis, reduction in sperm count, motility, histological changes in testis and variation in hormone level after 1st and 5th week of last injection in cyclophosphamide treated mice was an indication of drug toxicity.

The weight of the testis largely depends on the mass of the differentiated spermatogenic cells, a reduction in the organ weight may be attributed to decreased sperm production (Katoh et al., 2002). Our present results showed significant decrease in body weight observed with higher concentration of $200 \mathrm{mg} / \mathrm{kg}$ in both $1 \mathrm{st}$ and 5 th week of cyclophosphamide treated mice when compared to the control. Effect of cyclophosphamide administration (100 mg/kg body weight, ip, for five consecutive days) on albino rat after 3rd and 6th week of treatment showed decreased testis and cauda epididymal weight, sperm count, motility and viable spermatozoa and increased percentage of abnormal spermatozoa (abnormality in the mid piece region of the flagellum) (Kaur et al., 1997). The weight of the testis and epididymis were significantly decreased in dose-dependent cyclophosphamide treated animals of 1 st week group, whereas, reduction of weight of testis and epididymis were observed only in $200 \mathrm{mg} / \mathrm{kg}$ in the 5 th week group. Alternatively, after 5 th week of treatment there was recovery in weight of the testis and epididymis except in mice treated with high dose of cyclophosphamide ( $200 \mathrm{mg} / \mathrm{kg}$ ). It is concluded that the testicular toxicity in mice treated with high dose of cyclophosphamide [corresponding to the therapeutic dose of humans $\left(750 \mathrm{mg} / \mathrm{m}^{2}\right)$ equivalent to mouse $(210-220 \mathrm{mg} / \mathrm{kg})]$ were severe, whereas, those treated with low dose although were affected initially recovered at a later stage.

The effect of chemicals on sperm motion can be analyzed from the CASA system, useful for quantitative sperm motion analysis. In the present study, the motility of cauda epididymal sperm decreased with increasing concentrations of cyclophosphamide in 1st week group. Interestingly, sperm motility increased in all the doses of 5th week group except in higher dose $(200 \mathrm{mg} / \mathrm{kg})$. These results indicate that the sperm motility is revived after 5th week of last cyclophosphamide treatment. Both decreased sperm motility and increased sperm DNA damage can result from high levels of reactive oxygen species produced by leukocytes in semen (Aitken et al., 1998; Irvine et al., 2000). We hypothesize that the oxidative stress of cyclophosphamide leads to reduced sperm motility in 1st week and rejuvenation of motility after 5th week. Whereas, with higher dose of cyclophosphamide there might be complete damage to sperm in both 1st and 5th week group. Action of reactive oxygen species on spermatozoa resulted in decreased capacity for ionophore-induced acrosome reaction, decrease in sperm motility, increase in the concentration of lipid hydroperoxides and loss of membrane polyunsaturated fatty acids (Griveau et al., 1995). Environmental contaminants and drugs increase the levels of reactive oxygen species (ROS), which include superoxide anion, hydroxy radical, hydrogen peroxide, hypochlorite, etc. ROS affects the acrosome activity of human spermatozoa 

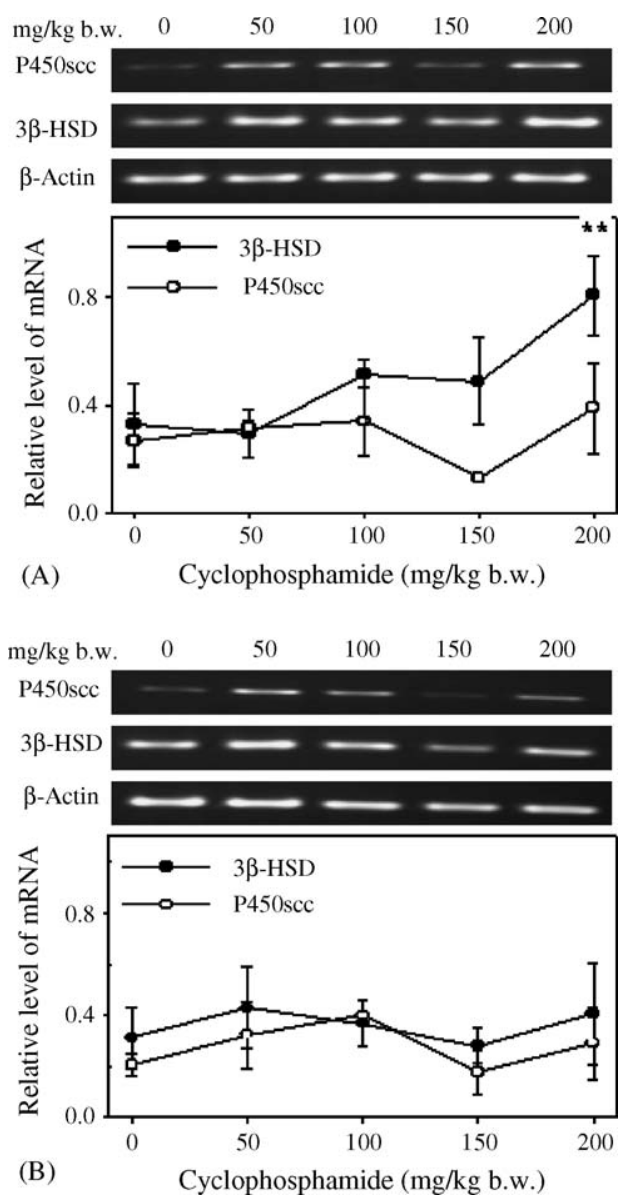

Fig. 4. Effect of cyclophosphamide on synthesis of testosterone enzymes in mouse testis (A) after 1st and (B) after 5th week of last injection. Dose related effects of cyclophosphamide on P450scc and $3 \beta$-HSD mRNA analyzed by semiquantitative RT-PCR. Representative signals (gel patterns) of mice from each dose are shown in the upper panels of (A) and (B). The figure exhibits relative levels of those RTPCR products to that of $\beta$-actin. Values are expressed as mean \pm S.D., $n=4,{ }^{* *} P<0.01$, compared with control groups.

(Ichikawa et al., 1999). In our study, we observed that mice treated with cyclophosphamide showed reduction in intact acrosome and viability of caudal epididymal sperm when exposed to both short and long term duration. As a result, the rate of fertility decreased considerably.

There is evidence that low dose $(5.1 \mathrm{mg} / \mathrm{kg})$ of chronic cyclophosphamide treatment of male rat can affect the outcome of its progeny (Trasler et al., 1986). Interestingly, male-mediated developmental toxicity was reported after oxidative stress; prooxidant treatment of male mice induced lethal mutations in offspring, resulting in increased postimplantation loss (Kumar and Muralidhara, 1999). In the present study, although permanent sterility was observed in male mice treated with high dose of cyclophosphamide there was no change in the number of offspring produced from female mice that were impregnated with male mice treated with low dose of cyclophosphamide. However, the ability of the female impregnation was lowered with dose dependent drug treatment and the vaginal plug formation was delayed in females, caged with male mice treated with increasing dose of cyclophosphamide.

Chemotherapy and/or X- or gamma-radiation therapy can result in long-term or permanent azoospermia, the mechanism of which is most likely the death of stem spermatogonia. The duration of azoospermia appears to be related to the proportion of stem cells killed; if all stem cells are killed, the azoospermia will be irreversible (Meistrich, 1986). In our study, the sperm count in the epididymis declined in a dose dependent manner in the 1st week group of mice. When the sperm count in 1st and 5th week groups were compared, there was recovery of sperm count in all doses of 5th week group except in higher dose. This process is critical which may be due to the damage in spermatogonia and hence the decrease in sperm counts. Spermatogenesis fails to recover not because stem spermatogonia are killed, but rather because surviving stem spermatogonia fail to differentiate (Kangasniemi et al., 1996). The presence of stem cells is a prerequisite for being able to stimulate recovery. Hence, it can be concluded from the present work that spermatogonia may survive after cyclophosphamide treatment but fail to differentiate with high dose. In the present study, histological studies revealed that some cells of spermatogonium (sperm stem cells) are resistant to damage with high dose of cyclophosphamide even after a period of 5 weeks. Nevertheless, other cells in the seminiferous tubules such as spermatocytes and spermatids are damaged by low dose of cyclophosphamide and leads to impaired spermatogenesis. Interestingly, the tubules with qualitatively normal spermatogenesis were observed in mice treated with low dose of cyclophosphamide even when exposed for longer duration. These observations suggest that spermatogonial cells are relatively resistant to cyclophosphamide, and that inactivation of only a fraction of sperm stem cells in a given tubule may have a disproportionately larger effect on spermatogenesis. Cyclophosphamide treatment had no effect on histopathological changes in advanced germ cells, although it resulted in a decreased number of early germ cells. Spermatogenesis is the development of mature spermatozoa from diploid spermatogonial cells and it completes in $\sim 75$ days in man and 35 days in mice (Clermont, 1963). Spermatogonia are also target cells of cyclophosphamide in the male reproductive system. Regarding the development and maturation 
of mouse sperm, it would be expected that cyclophosphamide exposed spermatogonia first appear in the cauda epididymis and mature into spermatozoa at the end of 5 th week.

Testicular function is influenced by both endocrine (extra-testicular) and paracrine (intra-testicular) factors. The intra-testicular regulation of spermatogenesis is thought to be carried out by steroids, such as testosterone and oestradiol, which are synthesized by the Leydig cells. Spermatogenesis in man and rodents does not proceed normally if the testis is deprived of endocrine support (McLachlan et al., 2002). Ethane dimethanesulfonate (EDS) and chloroethylmethanesulfonate (CMS) are alkylating antitumour agents that destroy Leydig cells and thus cause a reduction in testosterone (Klinefelter et al., 1992, 1994a,b). The inhibition of spermatogenesis may be due to low levels of plasma gonadotrophin and testosterone, which are prime regulators of spermatogenesis in rats (Means, 1975; Chowdhury, 1979). The decrease of testosterone in osteopetrosis mutated $\left(c s f m^{\mathrm{op}}\right)$ mice was associated with the alteration of Leydig cell function and a reduction in the conversion of cholesterol to pregnenolone by P450scc (Cohen et al., 1997). Our study demonstrates the adverse effect of cyclophosphamide on hormones involved in spermatogenesis. The increase in the FSH levels may contribute to the inhibition of spermatogonial differentiation and furthermore, the serum LH levels did not correlate with spermatogenic recovery after irradiation (Shetty et al., 2000, 2002). Our results showed that FSH was not significantly altered in cyclophosphamide treated mice in both 1st and 5th week. The LH was significantly down regulated in a dose dependent manner in the 1st week group. Decrease in serum testosterone, LH and FSH accompanies anticancer drug leuprolide treatment (Okada et al., 1994), its effects on seminiferous tubule repopulation are believed to be mediated by suppression of ITT levels (Meistrich and Kangasniemi, 1997; Meistrich, 1998). Significant decrease in plasma testosterone was observed after 1st and 5th weeks in mice exposed to cyclophosphamide. Decreased plasma testosterone indicates the detrimental effect on spermatogenesis.

Steroidogenic enzymes are sensitive indicators of testicular testosterone synthesis, the alterations of enzymes, which might result in change of testosterone synthesis. In the present study, we described the dose-response relationship of cyclophosphamide involved in the key steps in the steroidogenic pathway. The changes in gene expression were correlated with corresponding levels of testis testosterone (intratesticular testosterone) concentration. The failure of recovery of spermatogenesis to occur naturally in the rat appears to be related to the high intratesticular testosterone (ITT) concentrations and the stimulation of recovery by GnRH agonists to suppression of ITT (Meistrich and Kangasniemi, 1997). In the 1st week group high level of mRNA expression of $3 \beta$-HSD corresponded to high levels of intratesticular testosterone (ITT) in testis, indicating the failure of spermatogenesis. Alternatively, low level of $3 \beta$-HSD expression observed in the 5th week, resulting to the recovery of spermatogenesis in testis. These observations demonstrate that spermatogenic recovery in cyclophosphamide treated mice might be due to lowered testis testosterone level.

Based on the results from the present study it is concluded that chronic cyclophosphamide treatment of male mice alters spermatogenesis. Reduced fertility rate of mice after drug treatment may be due to the damage in male germ cells and hence resulting in altered sperm function and infertility. There was tendency of recovery in the spermatogenesis observed at lower doses of cyclophosphamide treated groups as compared to higher doses. Further studies are required in other models to confirm these findings.

\section{Acknowledgement}

The National Science Council (grant NSC93-2311B001-070), Taiwan, Republic of China, supported this work.

\section{References}

Aguilar-Mahecha, A., Hales, B.F., Robaire, B., 2005. Effects of acute and chronic cyclophosphamide treatment on meiotic progression and the induction of DNA double-strand breaks in rat spermatocytes. Biol. Reprod. 72, 1297-1304.

Aitken, R.J., Gordon, E., Harkiss, D., Twigg, J.P., Milne, P., Jennings, Z., 1998. Relative impact of oxidative stress on the functional competence and genomic integrity of human spermatozoa. Biol. Reprod. 59, 1037-1046.

Buchanan, J.D., Fairley, K.F., Barrie, J.U., 1975. Return of spermatogenesis after stopping cyclophosphamide therapy. Lancet 306 (7926), 156-157.

Charak, B.S., Gupta, R., Mandrekar, P., Sheth, N.A., Banavali, S.D., Saikia, T.K., Gopal, R., Dinshaw, K.A., Advani, S.H., 1990. Testicular dysfunction after cyclophosphamide-vincristineprocarbazine-prednisolone chemotherapy for advanced Hodgkin's disease. A long-term follow-up study. Cancer 65, 1903-1906.

Chowdhury, A.K., 1979. Dependence of testicular germ cells on hormone. A quantitative study in hypophysectomized testosterone treated rats. J. Endocrinol. 20, 911.

Clermont, Y., 1963. The cycle of the seminiferous epithelium in man. Am. J. Anat. 112, 35-51.

Cohen, P.E., Hardy, M.P., Pollard, J.W., 1997. Colony-stimulating factor-1 plays a major role in the development in male mice. Mol. Endocrinol. 11, 1636-1650. 
Crook, T.R., Souhami, R.L., McLean, A.E., 1986. Cytotoxicity, DNA cross-linking, and single strand breaks induced by activated cyclophosphamide and acrolein in human leukemia cells. Cancer Res. 46, 5029-5034.

Das, U.B., Mallick, M., Debnath, J.M., Ghosh, D., 2002. Protective effect of ascorbic acid on cyclophosphamide-induced testicular gametogenic and androgenic disorders in male rats. Asian J. Androl. 4, 201-207.

Dollery, C., 1999. Therapeutic Drugs. Churchill Livingstone, Edinburg, pp. C349-C354.

Fraiser, L.H., Kanekal, S., Kehrer, J.P., 1991. Cyclophosphamide toxicity. Characterizing and avoiding the problem. Drugs 42, 81-95.

Freireich, E.J., Gehan, E.A., Rall, D.P., 1966. Quantitative comparison of toxicity of anticancer agents in mouse, rat, hamster, dog, monkey and man. Cancer Chemother. Rep. 50, 219-244.

Ghosh, D., Das, U.B., Ghosh, S., Mallick, M., Debnath, J., 2002. Testicular gametogenic and steroidogenic activities in cyclophosphamide treated rat: a correlative study with testicular oxidative stress. Drug Chem. Toxicol. 25, 281-292.

Griveau, J.F., Dumont, E., Renard, P., Callegari, J.P., Lannou, D.Le., 1995. Reactive oxygen species, lipid peroxidation and enzymatic defence systems in human spermatozoa. J. Reprod. Fertil. 103, $17-26$.

Hemminki, K., Kallama, S., 1986. Reactions of nitrogen mustards with DNA. IARC Sci. Publ. 78, 55-70.

Higuchi, H., Nakaoka, M., Katsuda, Y., Kawamura, S., Kato, T., Matsuo, M., 1995. Collaborative assessment of optimal administration period and parameters to detect effects on male fertility in the rat: effects of cyclophosphamide on the male reproductive system. J. Toxicol. Sci. 20, 239-249.

Hoorweg-Nijman, J.J., Delemarre-vande-Wall, H.A., DeWall, F.C., Behrendt, H., 1992. Cyclophosphamide-induced disturbance of gonadotropin secretion manifesting testicular damage. Acta Endocrinol. 126, 143-148.

Hoshi, K., Katayose, H., Yanagida, K., Kimura, Y., Sato, A., 1996. The relationship between acridine orange fluorescence of sperm nuclei and the fertilizing ability of human sperm. Fertil. Steril. 66, 634-639.

Ichikawa, T., Oeda, T., Ohmori, H., Schill, W.B., 1999. Reactive oxygen species influence the acrosome reaction but not acrosin activity in human spermatozoa. Int. J. Androl. 22, 37-42.

Irvine, D.S., Twigg, J.P., Gordon, E.L., Fulton, N., Milne, P.A., Aitken, R.J., 2000. DNA integrity in human spermatozoa: relationships with semen quality. J. Androl. 21, 33-44.

Kangasniemi, M., Huhtaniemi, I., Meistrich, M.L., 1996. Failure of spermatogenesis to recover despite the presence of a spermatogonia in the irradiated $\mathrm{LBNF}_{1}$ rat. Biol. Reprod. 54, 1200-1208.

Katoh, C., Kitajima, S., Saga, Y., Kanno, J., Horii, I., Inoue, T., 2002. Assessment of quantitative dual-parameter flow cytometric analysis for the evaluation of testicular toxicity using cyclophosphamide and ethinylestradiol treated rats. J. Toxicol. Sci. 27, 87-96.

Kaur, F., Sangha, G.K., Bilaspuri, G.S., 1997. Cyclophosphamideinduced structural and biochemical changes in testis and epididymis of rats. Indian J. Exp. Biol. 35, 771-775.

Kenney, L.B., Laufer, M.R., Grant, F.D., Grier, H., Diller, L., 2001. High risk of infertility and long term gonadal damage in males treated with high dose cyclophosphamide for sarcoma during childhood. Cancer 91, 613-621.

Klinefelter, G.R., Laskey, J.W., Kelce, W.R., Ferrell, J., Roberts, N.L., Suarez, J.D., Slott, V., 1994a. Chloroethylmethanesulfonate induced effects on the epididymis seem unrelated to altered Leydig cell function. Biol. Reprod. 51, 82-91.
Klinefelter, G.R., Laskey, J.W., Perreault, S.D., Ferrell, J., Jeffay, S., Suarez, J.D., Roberts, N., 1994b. The ethane dimethanesulfonateinduced decrease in the fertilizing ability of cauda epididymal sperm is independent of the testis. J. Androl. 15, 318-327.

Klinefelter, G.R., Roberts, N.L., Suarez, J.D., 1992. Direct effects of ethane dimethanesulphonate on epididymal function in adult rats. An in vitro demonstration. J. Androl. 13, 409-421.

Kumar, T.R., Muralidhara, 1999. Male-mediated dominant lethal mutations in mice following prooxidant treatment. Mutat. Res. 444, $145-149$.

Lahdetie, J., 1983. Micronuclei induced during meiosis by ethyl methanesulfonate, cyclophosphamide and dimethylbenzanthracene in male rats. Mutat. Res. 120, 257-260.

Lahdetie, J., 1988. Induction and survival of micronuclei in rat spermatids. Comparison of two meiotic micronucleus techniques using cyclophosphamide. Mutat. Res. 203, 47-53.

Lee, M.A., Storey, B.T., 1986. Bicarbonate is essential for fertilization of mouse eggs; mouse sperm require it to undergo the acrosome reaction. Biol. Reprod. 34, 349-356.

Matsui, H., Mitsumori, K., Yasuhara, K., Onodera, H., Shimo, T., Takahashi, M., 1995. Morphological evaluation of cyclophosphamide testicular toxicity in rats using quantitative morphometry of spermatogenic cycle stages. J. Toxicol. Sci. 20, 407-414.

McLachlan, R.I., O’Donnell, L., Meachem, S.J., Stanton, P.G., de Kretser, D.M., Pratis, K., Robertson, D.M., 2002. Identification of specific sites of hormonal regulation in spermatogenesis in rats, monkeys, and man. Recent Prog. Horm. Res. 57, 49-79.

Means, A.R., 1975. Biochemical effect of follicle stimulating hormone on the testis. Handbook Physiol., 203-217.

Meistrich, M.L., 1986. Relationship between spermatogonial stem cell survival and testis function after cytotoxic therapy. Brit. J. Cancer 53, 89-101.

Meistrich, M.L., 1998. Hormonal stimulation of the recovery of spermatogenesis following chemo- or radiotherapy: review article. APMIS 106, 37-46.

Meistrich, M.L., Kangasniemi, M., 1997. Hormone treatment after irradiation stimulates recovery of rat spermatogenesis from surviving spermatogonia. J. Androl. 18, 80-87.

Okada, H., Doken, Y., Ogawa, Y., Toguchi, H., 1994. Sustained suppression of the pituitary-gonadal axis by leuprorelin three-month depot microspheres in rats and dogs. Pharm. Res. 11, 1199-1203.

Sancar, A., Lindsey-Boltz, L.A., Unsal-Kacmaz, K., Linn, S., 2004. Molecular mechanisms of mammalian DNA repair and the DNA damage checkpoints. Annu. Rev. Biochem. 73, 39-85.

Shetty, G., Wilson, G., Hardy, M.P., Niu, E., Huhtaniemi, I., Meistrich, M.L., 2002. Inhibition of recovery of spermatogenesis in irradiated rats by different androgens. Endocrinology 143, 3385-3396.

Shetty, G., Wilson, G., Huhtaniemi, I., Shuttlesworth, G.A., Reissmann, T., Meistrich, M.L., 2000. Gonadotropin-releasing hormone analogs stimulate and testosterone inhibits the recovery of spermatogenesis in irradiated rats. Endocrinology 141, 1735-1745.

Sotomayor, R.E., Cumming, R.B., 1975. Induction of translocations by cyclophosphamide in different germ-cell stages of male micecytological characterization and transmission. Mutat. Res. 27, 375-388.

Tates, A.D., 1992. Validation studies with the micronucleus test for early spermatids of rats. A tool for detecting clastogenicity of chemicals in differentiating spermatogonia and spermatocytes. Mutagenesis 7, 411-419.

Trasler, J.M., Hales, B.F., Robaire, B., 1986. Chronic low dose cyclophosphamide treatment of adult male rats: effect on fertility, pregnancy outcome and progeny. Biol. Reprod. 34, 275-283. 